\title{
"Stagging" and Flipping Activity: The Moderating Effect of IPOs Performance towards Market Momentums
}

\author{
Leow Hon $\mathrm{Wei}^{1}$ \\ ${ }^{1}$ Faculty of Business and Finance, Twintech International University College of Technology, Kuala Lumpur, \\ Malaysia \\ Correspondence: Persiaran Industri, Bandar Sri Damansara, 52200 Kuala Lumpur, Selangor, Canada. Tel: \\ 1-012-2737980. E-mail: leow.fbf@twintech.edu.my
}

Received: April 29, 2015

Accepted: May 15, 2015

Online Published: July 25, 2015

doi:10.5539/ijef.v7n8p265

URL: http://dx.doi.org/10.5539/ijef.v7n8p265

\begin{abstract}
Flipping activities provide liquidity and enhance IPOs efficiency; however, enormous "stagging" phenomenon may hurt the investors during the secondary market. This paper aims to study whether the effort of IPOs performance moderates the flipping activity in different market momentums. A quantitative research is adopted in this paper with a set of 344 IPOs data collected to proxy the flipping activities, IPOs initial performance and market momentums. Hierarchy regression is applied to analyze the interaction effect of moderating variable to the independent variable and dependent variable. The results revealed the following: market momentum of very cold IPOs helped in encouraging flipping activities on trading volume; hot IPOs helped in stimulating flipping activities for both trading volume and share offered. Nevertheless, there is a moderating effect of IPOs initial performance towards hot IPOs to affect flipping activities. The IPO market experiences active flipping activities in hot IPOs and very cold IPOs; to assist in predicting subsequent trading activity. It helps the underwriter to retain the stabilization of share prices, to prevent abnormal "stagging" activities and create market efficiency. From the investor's perspective, liquidity risk is reduced in regard to the IPOs performance through flipping activities.
\end{abstract}

Keywords: "stagging" phenomenon, flipping activities, market momentums, moderating effect, IPOs initial performance

\section{Introduction}

The winds of change in the emergence of IPOs studies on trading volume as measured by flipping activities have been on increasing interest in IPOs market in the recent years. In recent decades, trading volume is one of the major interesting subjects which studies on several variables, such as underwriter, proceeds from IPOs, initial performance of IPOs, exchange, market momentums and etc., with regard to the different degrees of flipping activity (Ellis et al., 2000; Aggarwal, 2003; Bayley, 2006). According to Ellis (2002), the first day trading volume rift to $70 \%$ of the shares sold in the IPOs. Hence, the flippers play the role as a perpetrator who receive the allocation of share and sell them in the first day of IPOs, in order to gain abnormal returns (Smith and Pulliam, 2000). This action will accelerate the "stagging" activity, affect the IPOs price stabilization and retention of IPOs. Normally, the underwriter will initially set the offer price below the share's fair value and offers it at a discounted price to attract investors. In quid pro quo, the flipping activity in stock market is more obvious where the investors intend to purchase new IPOs and hope to liquidate it in a short period of time (Correra, 1992). Thus, the initial performance of IPOs is affected by the share pricing, share allocation and flipping activity by investors (Aggarwal, 2003).

Moreover, Bayley (2006) defined flipping activity as volume of shares that are being sold and bought by the investors on the first day of IPO or total shares that being invested by investors prior to the listing of IPO; measured by the aftermarket trading. The purpose is to liquidate IPO allocation and from there, the underwriter and institutional investors are trying to create better returns of IPOs on the first day of trading to attract retail investors (Boehmer \& Fishe, 2000). Under normal circumstances, the shares are initially allocated for those investors before the listing and they tend to liquidate it on the first day of trading. Investors who buy a new issue and sell it even at a single point increase of the IPO share price are classified as 'flippers'. In other words, poor market price performance or over-pricing of the IPO will soar at the first day of trading in the aftermath of the 
flipping activity. In spite of that, existing flippers are not just creating problems in the market; conversely, it also contributes to smooth up the liquidity of secondary market for the IPO. For instance, if the IPO is only being held for a long term instead, then there will be no aftermarket trading and hence the share price will not change from the offer price, causing no role for the underwriter. Everything is good as long as the flipping activity does not overheat the primary market as a whole. In view of that, this paper examines the relationship and the moderating effect of the initial IPOs performance in the context of flipping activity.

Going forward, the flipping activity can be solved by averaging out the investors by dispersing out the share offers to different types of investor proverbially in order to prevent the tendency of few institution investors to monopoly the IPO issue on one hand and the volatility of the IPOs on the first day of trading. Therefore, it can be coped within the power of the underwriter. According to Ellis (2006), in the best knowledge of flippers, they sell the shares from their holding to gain benefit from the price appreciation on the first day of trading and it is more obvious on the hot IPOs with high trading volume than cold IPOs. She examined the enormous trading volume to the flipping activities on the first and second days of trading with the cold and hot IPOs as the independent variables for her study. Hence, the different characteristics of market momentums, such as hot IPOs, warm IPOs, cold IPOs and very cold IPOs have an impact and play a vital role to influence the flipping activity of IPOs.

This paper further study the different characteristics of market momentums by studying the relationships between hot IPOs, warm IPOs, cold IPOs and very cold IPOs with flipping activity and also investigates the interaction effect by the IPOs initial performance to the flipping activity on IPOs. The objective of this study is to examine how the IPOs initial performance will affect the market momentums in the occurrence of the investor's activity. Therefore, this study is hoped to benefit the underwriter, issuer, institutional investors and retail investors; those who are willing to bid above the offered price and hold on to it for a long term to avoid any unexpected loss.

The rest of the paper is structured as follows: Section 2 discusses the past relevant literature review, Section 3 describes the data and methodology used in this study, Section 4 presents the main results and lastly, Section 5 concludes the findings.

\section{Literature Review}

Boehmer and Fishe (2000) and Fishe (2001) had developed a model to explicate flipping activity is necessarily induced by initial performance and there have been several studies in the literature reporting the relationship between IPOs initial performance (as proxied by underpricing) and aftermarket trading volume (as proxied by flipping activity). Miller and Reilly (1987), Schultz and Zaman (1994) and Ellis et al. (2000) had argued that there is a positive relationship between the IPOs initial performance and the flipping activity. The finding is consistent with Chong (2009) on the disposition effect using 132 Malaysian IPOs from 1991 to 2003, which also reported a positive relationship between initial performance and the flipping activity.

In the capital market of US, flipping activity is more aggressive on the less concerned and overpriced IPOs. The importance of flipping activity was studied by Krigman et al. (1999) and they concluded that the flipper was smart to exit the market quickly because higher IPOs flipping activity performed the lowest initial performance in the long run. The pricing error is the culprit, which causes poor initial performance with the flipping activity on this negative relationship. Also, institutional investors flip more on poor IPOs initial performance. Likewise, according to Islam and Munira (2004), who used 96 Dhaka IPOs from 1994 to 2001, a small IPOs being issued had a higher flipping activity by flippers, compared to huge IPOs. Research finding by Bayley et al. (2006) also pointed towards a significant negative relationship between size issued and flipping activity, by using 457 IPOs issued from 1995 to 2000.

Conversely, in the primary market, there is a common belief of the existence of 'flippers' who are allocated with IPO shares and quickly to liquidate them on the first trading day, and it is obviously supported by the high trading volume. Aggarwal (2003) found out that flipping activities occurred in 19\% of the trading volume and 15\% of shares offered. Meanwhile, flipping activity in hot IPOs are much higher than the cold IPOs but the supporting price on the IPOs lead the institutional investors to flip more on cold IPOs than hot IPOs. Therefore, the experimental data are rather controversial and there is no general agreement whether flipping activity occurs more often in hot or cold IPOs, and this paper is aimed to examine the reliable evidence on the market momentums.

Moreover, results from Ellis (2006) are consistent with Aggarwal (2003), which showed that the flippers sell shares at a higher price in hot IPOs than cold IPOs. However, this result was contradicted by the experiments of Krigman et al. (1999), who considered the US IPOs from 1988 to 1995 and showed that the flipping activity is 
higher in frequency in cold IPOs compared to hot IPOs, together with $45 \%$ and $22 \%$ of the initial trading volumes, respectively. Overall, previous studies showed that numerous factors are significant to explicate flipping activity. However, far too little attention has been paid to the study of the moderating role of initial performance of IPOs together with the interaction effect in different market momentums, such as very cold IPOs, cold IPOs, warm IPOs and hot IPOs on flipping activity. Hence, the conceptual framework is developed as below:

\begin{tabular}{|c|c|c|}
\hline Very Cold IPO (CCIPO) & $\mathrm{H} 3$ and $\mathrm{H} 4 \quad \downarrow$ moderate & Flipping as the percentage of \\
\hline $\begin{array}{l}\text { Warm IPO (WIPO) } \\
\text { Hot IPO (HIPO) }\end{array}$ & $\mathrm{H} 1$ and $\mathrm{H} 2$ & Flipping as the percentage of \\
\hline Initial Performance (UIPO) & & $\begin{array}{l}\text { market trading volume } \\
\text { (FMTO) }\end{array}$ \\
\hline
\end{tabular}

Figure 1. The conceptual framework

\section{Data and Methodology}

This study used a sample comprised of 344 IPOs listed on the Bursa Malaysia from the period of January 1, 2001 to December 31, 2011. Data were compiled from the Investor Digest, a monthly publication of the Bursa Malaysia, Bursa Malaysia website, The Star Online, Thompson Reuters and Bloomberg. The dependent variables consisted of flipping activity based on share offered (FSO) and flipping activity based on market trading volume (FMTO). FSO refers to the shares flipped as the percentage of IPO trading volume with the IPO total share offered on the first day of trading. FMTO refers to the shares flipped as the percentage of IPO trading volume with the market trading volume on the first day of trading (Aggarwal, 2003). Meanwhile, the moderator variable was IPOs initial performance (UIPO) derived from initial return (offer-to-close) by calculating the initial performance of IPO, $i$ measured as UIPO ${ }_{i}=\left[\left(\mathrm{P}_{\mathrm{c}}-\mathrm{P}_{\mathrm{o}}\right) / \mathrm{P}_{\mathrm{o}}\right]$ x 100, where $\mathrm{UIPO}_{\mathrm{i}}$ represented total return at the closing on the first trading day (offer-to-close), $\mathrm{P}_{\mathrm{c}}$ represented the price of the IPO stock at the closing on the first trading day and the $\mathrm{P}_{\mathrm{o}}$ represented the offer price of the IPOs.

In addition, this study hypothesized the moderating effect of UIPO with flipping activities in different market momentums. This paper split out the IPOs based on four market momentums, which consisted of very cold IPO (CCIPO), cold (CIPO), warm IPO (WIPO), and hot IPO (HIPO) as the independent variables. According to Aggarwal (2003), CCIPO captures the IPOs with a first day of return less than zero percent, CIPO captures the IPOs with a first day of return from zero percent to ten percent, WIPO captures the IPOs with a first day of return from ten percent to sixty percent, and lastly, HIPO captures the IPO with a first day of return greater than sixty percent. The hypotheses are developed as below:

H1: $\alpha$ not equal to 0

$$
\mathrm{FSO}_{i}=\alpha_{0}+\alpha_{1} \mathrm{UIPO}_{i}+\alpha_{2} \mathrm{CCIPO}_{i}+\alpha_{3} \mathrm{CIPO}_{i}+\alpha_{4} \mathrm{WIPO}_{i}+\alpha_{5} \mathrm{HIPO}_{i}+\varepsilon_{i}
$$

$\mathrm{H} 2: \beta$ not equal to 0

$$
\mathrm{FMTO}_{i}=\beta_{0}+\beta_{1} \mathrm{UIPO}_{i}+\beta_{2} \mathrm{CCIPO}_{i}+\beta_{3} \mathrm{CIPO}_{i}+\beta_{4} \mathrm{WIPO}_{i}+\beta_{5} H I P O_{i}+\varepsilon_{i}
$$

In the analysis, this research tested hypotheses 1 and 2 using multiple regressions to examine how the independent variables of market momentums (CCIPO, CIPO, WIPO and HIPO) influence the relationships of flipping activities, as measured by FSO and FMTO.

Going forward for hypotheses 3 to 4 using hierarchy regression, this research further examined the moderating effect of UIPO toward the FSO and FMTO with different market momentums, to better explain the interaction effect of the flipping activities. In order to study the moderating effect of UIPO and market momentums to the flipping activities of IPOs, this paper developed four models of time varying flipping activities with CCIPO, CIPO, WIPO and HIPO. Flipping activities acted as the dependent variables in each of the hierarchical regression models and market momentum input as block one, as per model 3.1 and model 4.1. The UIPO is treated as a moderating variable to examine the interaction effects in block 1 and input as block 2, as per model 3.2 and model 4.2 . 
H3: UIPO moderates the relationship between market momentums and flipping activity (FSO)

$$
\begin{gathered}
\text { (Block 1) } \mathrm{FSO}_{\mathrm{i}}=\gamma_{0}+\gamma_{1} \mathrm{CCIPO}_{\mathrm{i}}+\gamma_{2} \mathrm{CIPO}_{\mathrm{i}}+\gamma_{3} \mathrm{WIPO}_{\mathrm{i}}+\gamma_{4} \mathrm{HIPO}_{\mathrm{i}}+\varepsilon_{\mathrm{i}} \\
\text { (Block 2) } \mathrm{FSO}_{\mathrm{i}}=\gamma_{5}+\gamma_{6} \mathrm{UIPO}_{\mathrm{i} C C I P O}+\gamma_{7} \mathrm{UIPO}_{\mathrm{i}} \mathrm{CIPO}_{\mathrm{i}}+\gamma_{8} \mathrm{UIPO}_{\mathrm{i}} \mathrm{WIPO}_{\mathrm{i}}+\gamma_{9} \mathrm{UIPO}_{\mathrm{i}} \mathrm{HIPO}_{\mathrm{i}}+\varepsilon_{\mathrm{i}}
\end{gathered}
$$

H4: UIPO moderates the relationship between market momentums and flipping activity (FMTO)

$$
\text { (Block 1) } \mathrm{FMTO}_{\mathrm{i}}=\theta_{0}+\theta_{1} \mathrm{CCIPO}_{\mathrm{i}}+\theta_{2} \mathrm{CIPO}_{\mathrm{i}}+\theta_{3} \mathrm{WIPO}_{\mathrm{i}}+\theta_{4} \mathrm{HIPO}_{\mathrm{i}}+\varepsilon_{\mathrm{i}}
$$

(Block 2) FMTO $_{i}=\theta_{5}+\theta_{6} \mathrm{UIPO}_{\mathrm{i}} \mathrm{CCIPO}_{\mathrm{i}}+\theta_{7} \mathrm{UIPO}_{\mathrm{i}} \mathrm{CIPO}_{\mathrm{i}}+\theta_{8} \mathrm{UIPO}_{\mathrm{i}} \mathrm{WIPO}_{\mathrm{i}}+\theta_{9} \mathrm{UIPO}_{\mathrm{i}} \mathrm{HIPO}_{\mathrm{i}}+\varepsilon_{\mathrm{i}}$

From the 4 hypotheses, $\mathrm{FSO}_{i}$ is the flipping activity represented by the percentage of trading volume to the shared offered on the first day of trading of the $i$ th company. $F M T O_{i}$ is the flipping activity represented by the percentage of trading volume on the first day of trading of the $i$ th company to the market trading volume. $C C I P O_{i}$ is very cold IPO represented by IPO with a first day of return less than $0 \%$ of the $i$ th company. $C I P O_{i}$ is cold IPO represented by IPO with a first day of return less than $10 \%$ of the $i$ th company. WIPO $i$ is warm IPO represented by IPO with a first day of return less than $60 \%$ of the $i$ th company. $H I P O_{i}$ is hot IPO represented by IPO with a first day of return more than $60 \%$ of the $i$ th company.

\section{Results}

Table 1. The sample of IPOs is divided based on very cold IPOs, cold IPOs, warm IPOs and hot IPOs. Flipping activity by the percentage of trading volume to the shared offered (FSO) and by the percentage of company

\begin{tabular}{|c|c|c|c|c|c|c|c|c|}
\hline & \multicolumn{2}{|c|}{ Very Cold IPOs } & \multicolumn{2}{|c|}{ Cold IPOs } & \multicolumn{2}{|c|}{ Warm IPOs } & \multicolumn{2}{|c|}{ Hot IPOs } \\
\hline & \multirow{2}{*}{\multicolumn{2}{|c|}{$\begin{array}{c}\text { day } 1 \text { return } \\
<=0 \%\end{array}$}} & \multicolumn{2}{|c|}{ day 1 return } & \multicolumn{2}{|c|}{ day 1 return } & \multicolumn{2}{|c|}{ day 1 return } \\
\hline & & & & & & & & \\
\hline & \multicolumn{2}{|c|}{$\mathrm{n}=102$} & \multicolumn{2}{|c|}{$\mathrm{n}=69$} & \multicolumn{2}{|c|}{$\mathrm{n}=124$} & \multicolumn{2}{|c|}{$\mathrm{n}=49$} \\
\hline & Mean & Median & Mean & Median & Mean & Median & Mean & Median \\
\hline UIPO & -14.56 & -8.31 & 5.05 & 4.63 & 29.00 & 25.69 & 116.16 & 96.67 \\
\hline $\begin{array}{l}\text { Shared flipped as \% of } \\
\text { total trading volume }\end{array}$ & 24.88 & 16.70 & 40.63 & 24.23 & 36.59 & 20.98 & 51.41 & 29.00 \\
\hline $\begin{array}{c}\text { Shared flipped as \% of } \\
\text { total shared offered }\end{array}$ & 60.13 & 25.11 & 62.15 & 41.04 & 61.93 & 35.36 & 116.82 & 46.12 \\
\hline
\end{tabular}
trading volume to the market trading volume (FMTO) with IPOs initial performance for the period of Jan 2001 to Dec 2011

In Table 1, the sample of the research is split into very cold, cold, warm and hot IPOs. There were 102 very cold IPOs with the UIPO mean return of zero percent or less, 69 IPOs were cold with the UIPO mean return of zero percent to less than or equal to $10 \%, 124$ IPOs were classified as warm IPOs with the UIPO mean return of between $10 \%$ to $60 \%$, and 49 IPOs were hot IPOs with UIPO mean return greater than $60 \%$. All these classifications are consistent with the results reported by Krigman et al. (1999). Mean flipping reported 24.88\% of the total trading volumes in very cold IPOs, $40.63 \%$ in cold IPOs, $36.59 \%$ in warm IPOs and $51.41 \%$ in hot IPOs. These results contradicted with Aggarwal (2003) and showed that flipping activities occurred most of the times in hot IPOs. In addition, results are in line with the low trading volume in very cold IPOs from the mean flipping activities of $60.13 \%$ to $116.82 \%$ reported in hot IPOs. Therefore, the dimension of flipping activities measured is considered much deeper in hot IPOs.

Furthermore, since the flipping activities provide stabilization on IPOs price, according to Chowdhry and Nanda (1996), original investors should flip more to alleviate the 'stagging' and it is obviously shown in hot IPOs. However, the results are contrary with the belief that investor flips more frequently during very cold or cold IPOs when underwriter is still providing the price support on IPOs. 
Table 2. Hierarchical regression on the moderation effect of IPO initial performance to the different market momentums and flipping activity by the percentage of trading volume to the shared offered (FSO) and flipping activity by the percentage of company trading volume to the market trading volume (FMTO) for the period of Jan 2001 to Dec 2011

\begin{tabular}{|c|c|c|c|c|}
\hline \multirow{3}{*}{ Independent Construct } & \multicolumn{2}{|c|}{ FSO } & \multicolumn{2}{|c|}{ FMTO } \\
\hline & Initial Block 1 & Moderated Block 2 & Initial Block 1 & Moderated Block 2 \\
\hline & \multicolumn{2}{|c|}{ unstd.coefficient / std. coefficient } & \multicolumn{2}{|c|}{ unstd.coefficient / std. coefficient } \\
\hline Constant & $\begin{array}{l}73.11 /- \\
(9.26)^{* *}\end{array}$ & $\begin{array}{l}73.11 /- \\
(9.25)^{* *}\end{array}$ & $\begin{array}{c}40.74 /- \\
(13.89)^{* *}\end{array}$ & $\begin{array}{l}40.74 / \text { - } \\
(13.87)^{* *}\end{array}$ \\
\hline CCIPO & $\begin{array}{c}-12.97 /-0.05 \\
(-0.90)\end{array}$ & $\begin{array}{c}-5.66 /-0.02 \\
(-0.31)\end{array}$ & $\begin{array}{c}-15.86 /-0.16 \\
(-2.94)^{* *}\end{array}$ & $\begin{array}{c}-14.16 /-0.14 \\
(-2.07)^{* *}\end{array}$ \\
\hline$C C I P O * U I P O$ & $\begin{array}{l}- \\
-\end{array}$ & $\begin{array}{c}0.50 / 0.04 \\
(-0.64)\end{array}$ & - & $\begin{array}{c}0.12 / 0.03 \\
(-0.40)\end{array}$ \\
\hline Durbin-Watson & \multicolumn{2}{|c|}{1.88} & \multicolumn{2}{|c|}{1.92} \\
\hline $\mathrm{R}^{2} /\left(\mathrm{R}^{2}\right.$ change $)$ & 0.15 & $(0.00)$ & 0.16 & $(0.03)$ \\
\hline F-value/ (F change) & 0.80 & $(0.41)$ & 8.66 & $(0.16)$ \\
\hline p-value & 0.37 & 0.52 & 0.00 & 0.69 \\
\hline Constant & $\begin{array}{l}71.04 /- \\
(9.59)^{* *}\end{array}$ & $\begin{array}{l}71.04 /- \\
(9.57)^{* *}\end{array}$ & $\begin{array}{c}34.89 /- \\
(12.55)^{* *}\end{array}$ & $\begin{array}{c}34.89 /- \\
(12.52)^{* *}\end{array}$ \\
\hline CIPO & $\begin{array}{c}-8.89 /-0.03 \\
(-0.54)\end{array}$ & $\begin{array}{c}-12.27 /-0.04 \\
(-0.38)\end{array}$ & $\begin{array}{c}5.74 / 0.05 \\
(0.92)\end{array}$ & $\begin{array}{c}4.57 / 0.04 \\
(0.38)\end{array}$ \\
\hline CIPO*UIPO & - & $\begin{array}{c}0.67 / 0.01 \\
(-0.12)\end{array}$ & - & $\begin{array}{c}0.23 / 0.01 \\
(0.11)\end{array}$ \\
\hline Durbin-Watson & \multicolumn{2}{|c|}{1.88} & \multicolumn{2}{|c|}{1.88} \\
\hline $\mathrm{R}^{2} /\left(\mathrm{R}^{2}\right.$ change $)$ & 0.15 & $(0.00)$ & 0.16 & $(0.00)$ \\
\hline F-value/ (F change) & 0.69 & $(0.05)$ & 0.85 & $(0.01)$ \\
\hline p-value & 0.41 & 0.83 & 0.26 & 0.91 \\
\hline Constant & $\begin{array}{l}73.39 /- \\
(8.86)^{* *}\end{array}$ & $\begin{array}{l}73.39 /- \\
(8.85)^{* *}\end{array}$ & $\begin{array}{c}35.73 /- \\
(11.47)^{* *}\end{array}$ & $\begin{array}{c}35.73 /- \\
(11.45)^{* *}\end{array}$ \\
\hline$W I P O$ & $\begin{array}{c}-11.46 /-0.05 \\
(-0.83)\end{array}$ & $\begin{array}{c}-6.38 /-0.03 \\
(-0.23)\end{array}$ & $\begin{array}{c}0.87 / 0.01 \\
(0.17)\end{array}$ & $\begin{array}{c}-0.10 / 0.00 \\
(-0.01)\end{array}$ \\
\hline WIPO*UIPO & - & $\begin{array}{c}-0.175 /-0.02 \\
(-0.21)\end{array}$ & - & $\begin{array}{c}0.03 / 0.01 \\
(0.11)\end{array}$ \\
\hline Durbin-Watson & \multicolumn{2}{|c|}{1.88} & \multicolumn{2}{|c|}{1.87} \\
\hline $\mathrm{R}^{2} /\left(\mathrm{R}^{2}\right.$ change $)$ & 0.15 & $(0.00)$ & 0.16 & $(0.00)$ \\
\hline F-value/ (F change) & 0.69 & $(0.05)$ & 0.03 & $(0.01)$ \\
\hline p-value & 0.41 & 0.83 & 0.87 & 0.91 \\
\hline Constant & $\begin{array}{l}61.36 /- \\
(8.68)^{* *}\end{array}$ & $\begin{array}{l}61.36 /- \\
(8.88)^{* *}\end{array}$ & $\begin{array}{l}33.49 /- \\
(12.56)^{* *}\end{array}$ & $\begin{array}{l}33.49 /- \\
(12.80)^{* *}\end{array}$ \\
\hline HIPO & $\begin{array}{c}55.45 / 0.16 \\
(2.96)^{* *}\end{array}$ & $\begin{array}{c}-104.55 /-0.30 \\
(-2.43)^{* *}\end{array}$ & $\begin{array}{c}17.92 / 0.14 \\
(2.54)^{* *}\end{array}$ & $\begin{array}{c}-37.49 /-0.28 \\
(-2.30)^{*}\end{array}$ \\
\hline$H I P O * U I P O$ & - & $\begin{array}{c}1.38 / 0.50 \\
(4.10)^{* *}\end{array}$ & - & $\begin{array}{c}0.48 / 0.46 \\
(3.75)^{* *}\end{array}$ \\
\hline Durbin-Watson & \multicolumn{2}{|c|}{1.90} & \multicolumn{2}{|c|}{1.91} \\
\hline $\mathrm{R}^{2} /\left(\mathrm{R}^{2}\right.$ change $)$ & 0.15 & $(0.03)$ & 0.16 & $(0.04)$ \\
\hline F-value/ (F change) & 8.77 & $(16.82)$ & 6.44 & 14.07 \\
\hline $\mathrm{p}$-value & 0.00 & 0.00 & 0.01 & 0.00 \\
\hline
\end{tabular}

Notes. Dependent variable -FSO and FMTO; UIPO - Underpricing; CCIPO - Very Cold IPO; CIPO -Cold IPO; WIPO -Warm IPO; HIPO Hot IPO, and significance at $5 \%$ and $1 \%$ level as indicated by $*$ and $* *$ respectively.

Table 2 shows that there is no relationship between very cold IPOs, cold IPOs and warm IPOs with flipping activities but very cold IPOs have a positive relationship with flipping activities on total market trading volume with the standardized coefficient equal to -0.16 at 1 percent confident level. Moreover, hot IPOs also have a positive relationship with flipping activities on total shared offered with the standardized coefficient equal to 0.16 at 1 percent confident level. Similar results with flipping activities on total market trading volume are 
reported with the standardized coefficient equal to 0.14 at 1 percent confident level. Therefore, this paper rejects the null hypothesis and confirmed $\mathrm{H} 1$ and $\mathrm{H} 2$, that at least one of the market momentums are in a relationship with flipping activities.

Table 2 further extends the results to explicate the moderating role of IPOs initial performance to the interaction effect of the market momentums, such as very cold IPOs, cold IPOs, warm IPOs, and hot IPOs to the flipping activities. This paper performed four hierarchical regression models in hypotheses testing. In each model, each market momentums (very cold IPOs, cold IPOs, warm IPOs and hot IPOs) were the independent variables and the dependent variable was the flipping activities. To compute the interaction effect, each of the market momentums were inputted as block one, and then followed by the moderating variable of IPOs initial performance was inputted as block two. The same process was assessed and repeated on different market momentums.

Going forward to the results of the moderating role of initial performance, there is no interaction effect between very cold IPOs, cold IPOs and warm IPOs with the flipping activities and it is concluded that IPOs initial performance does not moderate the relationship between market momentums and flipping activities. However, there is an interaction effect of IPOs initial performance to the relationship between hot IPOs and flipping activities, as reported in FSO with the standardized coefficient equal to -0.30 at 1 percent confident level and FMTO with the standardized coefficient equal to -0.28 at 1 percent confident level. Therefore, this paper rejects the null hypothesis and confirmed $\mathrm{H} 3$ and $\mathrm{H} 4$, where the initial performance does moderate the relationship between at least one of the market momentums with flipping activities, and the interaction effects of IPOs initial performance had a significant impact on flipping activities. Figure 2 shows the final framework for the overall results.

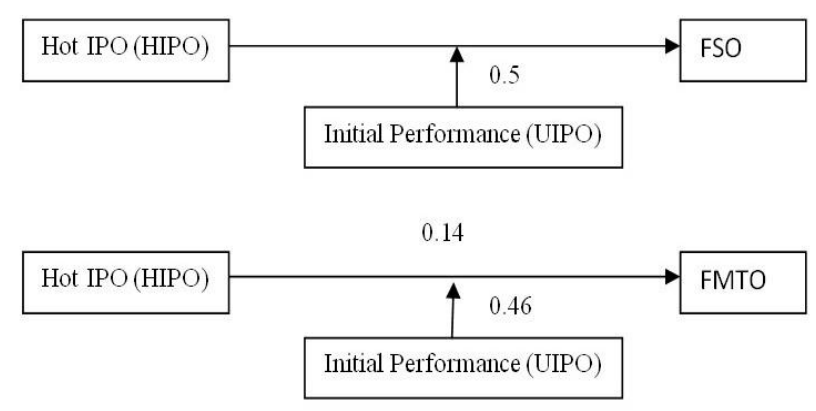

Figure 2. The final framework with significant relationship

\section{Conclusions}

This paper attempts to resolve and further enhance the issues from previous literature: (1) Do flipping activities in different market momentums help to predict the subsequent trading volume, especially for the stagging activities? (2) Does the market efficiency can be created by underwriter through flipping activities? (3) Does the initial performance of IPOs moderate the flipping activities? (4) Can the liquidity risk impose to investors be reduced through flipping activities? It is found that the market momentums of very cold IPOs and hot IPOs do encourage the flipping activities on trading volume, however only hot IPOs stimulate flipping activities on both trading volume and share offered. Therefore, it is concluded that the IPO market experiences active flipping activities in hot IPOs and very cold IPOs to assist in predicting subsequent trading activity. The high flipping activities in IPOs will help underwriter to stabilize the IPO prices, to avoid "stagging" activities and hence, achieve and retain market efficiency.

In addition, initial performance of IPOs moderates the relationship between hot IPOs and flipping activities. Only the initial performance of IPOs interacts with hot IPOs to affect flipping activities. The interaction effect of initial performance is reflected in investors to flip with higher frequency in hot market compared to others. Therefore, since the flipping activities increased, this will cause the liquidity risk to be reduced and became beneficial to the investors. Last but not least, this study does not mean without limitations. However, it also reflects the future research on flipping activities. First, the IPO quality of this research can be affected by the information from the institutional investors. Second, underwriters can easily underprice or overprice the IPOs intentionally through manipulation. Third, the time horizon of the research on IPO can be widened, not only on the first trading day. Despite the above limitations, it is believed that this paper provides interesting outcomes 
since it has a deeper discussion on the interaction effects of IPOs performance on different market momentums of flipping activities.

\section{Acknowledgements}

I would like to express the deepest appreciation to my supervisor from University, for his guidance and persistent help. His spirit of adventure in regard to research enlightens me continuously. In addition, special thanks to Tengku of Twintech University for his supports to make the research successful. Lastly, I acknowledge the suggestion and comment provided by the anonymous referee.

\section{References}

Aggarwal, R. (2003). Allocation of initial public offerings and flipping activity. Journal of Financial Economics, 68, 111-135. http://dx.doi.org/10.1016/S0304-405X(02)00250-7

Bayley, L., Lee, P. J., \& Walter, T. S. (2006). IPO flipping in Australia: Cross sectional explanations. Pacific-Basin Finance Journal, 14, 327-348. http://dx.doi.org/10.1016/j.pacfin.2006.01.002

Boehmer, E., \& Fishe, R. P. H. (2000). Do underwriters encourage stock flipping? A new explanation for the under-pricing of IPOs. Working Paper, University of Miami.

Chong, F. N. (2009). Disposition effect and flippers in the Bursa Malaysia. Journal of Behavioral Finance, 10(3), 152-157. http://dx.doi.org/10.1080/15427560903167712

Chowdhry, B., \& Nanda, V. (1996). Stabilization, syndication and pricing of IPOs. Journal of Finance and Quantitative Analysis, 31, 25-42. http://dx.doi.org/10.2307/2331385

Correra, A. J. (1992). Block that sale: War on IPO flippers hurts little guy. Barron's National Business and Financial Weekly, 72, 43.

Ellis, K., Michaely, R., \& O'Hara, M. (2000). When the underwriter is the market maker: An examination of trading in the IPO aftermarket. Journal of Finance, 55, 1039-1074. http://dx.doi.org/10.1111/0022-1082.00240

Ellis, K., Michaely, R., \& O'Hara, M. (2002). The making of a dealer market: from entry to equilibrium in the trading of Nasdaq stock. Journal of Finance, 57, 2289-2316. http://dx.doi.org/10.1111/1540-6261.00496

Ellis, K. (2006). Who trades IPOs? A close look at the first days of trading. Journal of Financial Economics, 79, 339-363. http://dx.doi.org/10.1016/j.jfineco.2004.09.006

Fishe, R. P. H. (2002). How stock flippers affect IPO pricing and stabilization. Journal of Financial and Quantitative Analysis, 37, 319-340. http://dx.doi.org/10.2307/3595008

Islam, M. S., \& Munira, S. (2004). IPO Flipping and its determinants in Bangladesh. Dhaka University Journal of Business Studies, 25(1), 1-23.

Krigman, L., Shaw, W. H., \& Womack, K. (1999). The persistence of IPO mispricing and the predictive power of flipping. Journal of Finance, 3, 1015-1044. http://dx.doi.org/10.1111/0022-1082.00135

Miller, R. E., \& Reilly, F. K. (1987). An examination of mispricing, returns, and uncertainty for initial public offerings. Financial Management, 16, 33-38. http://dx.doi.org/10.2307/3666001

Pulliam, S., \& Smith, R. (2000). Trade-offs: Seeking IPO shares, investors offer to buy more in after-market and pledges can be a factor, underwriters say, though they deny quid pro quo trying to avoid the flippers. Wall Street Journal February, 2, C1.

Schultz, P. H., \& Zaman, M. A. (1994). Aftermarket support and underpricing of initial public offerings. Journal of Financial Economics, 35, 199-219. http://dx.doi.org/10.1016/0304-405X(94)90004-3

\section{Copyrights}

Copyright for this article is retained by the author(s), with first publication rights granted to the journal.

This is an open-access article distributed under the terms and conditions of the Creative Commons Attribution license (http://creativecommons.org/licenses/by/3.0/). 